RESEARCH ARTICLE

\title{
A Three-wave Study of Antecedents of Work-Family Enrichment: The Roles of Social Resources and Affect
}

\author{
Oi Ling Siu ${ }^{1{ }^{\dagger}}$, Arnold B. Bakker ${ }^{2}$, Paula Brough ${ }^{3}$, Chang-qin Lu ${ }^{4}$, Haijiang Wang ${ }^{4}$, \\ Thomas Kalliath $^{5}$, Michael O'Driscoll ${ }^{6}$, Jiafang Lu $^{7} \&$ Carolyn Timms $^{3}$ \\ ${ }^{1}$ Lingnan University, Tuen Mun, Hong Kong \\ ${ }^{2}$ Erasmus University, Rotterdam, The Netherlands \\ ${ }^{3}$ Griffith University, Brisbane, Australia \\ ${ }^{4}$ Peking University, Beijing, China \\ ${ }^{5}$ Australian National University, Canberra, Australia \\ ${ }^{6}$ Waikato University, Hamilton, New Zealand \\ ${ }^{7}$ Hong Kong Institute of Education, Tai Po, Hong Kong
}

\begin{abstract}
On the basis of conservation of resources theory (Hobfoll, 1989) and the resource-gain-development perspective (Wayne, Grzywacz, Carlson, \& Kacmar, 2007), this paper examines the differential impact of specific social resources (supervisory support and family support) on specific types of affect (job satisfaction and family satisfaction, respectively), which, in turn, influence work-to-family enrichment and family-to-work enrichment, respectively. A sample of 276 Chinese workers completed questionnaires in a three-wave survey. The model was tested with structural equation modelling. Job satisfaction at time 2 partially mediated the relationship between time 1 supervisory support and time 3 work-to-family enrichment (capital), and the effect of supervisory support on work-to-family enrichment (affect) was fully mediated by job satisfaction. Family satisfaction at time 2 fully mediated the relationship between time 1 family support and time 3 family-to-work enrichment (affect, efficiency). Implications for theory, practice and future research are discussed. Copyright $\odot 2013$ John Wiley \& Sons, Ltd.
\end{abstract}

Received 15 June 2013; Revised 27 October 2013; Accepted 30 October 2013

Keywords

family satisfaction; family support, job satisfaction; supervisory support; work-family enrichment

*Correspondence

Oi Ling Siu, Department of Sociology and Social Policy, Lingnan University, Tuen Mun, NT, Hong Kong.

${ }^{\dagger}$ Email: siuol@|n.edu.hk

Published online in Wiley Online Library (wileyonlinelibrary.com) DOI: 10.1002/smi.2556

\section{Introduction}

The majority of work-family research has focused on the negative spillover of work stressors and possible consequences for the family domain (e.g. workfamily conflict; see review by Eby, Casper, Lockwood, Bordeaux, \& Brinley, 2005). Recently, in line with the positive psychology movement (Seligman \& Csikszentmihalyi, 2000), work-family interface research has also included positive spillover (Bakker \& Schaufeli, 2008; Brough, O'Driscoll, Kalliath, Cooper, \& Poelmans, 2009; Grzywacz \& Marks, 2000), which reflects support, facilitation or enrichment (the positive path; Carlson, Kacmar, Wayne, \& Grzywacz, 2006). Greenhaus and Powell (2006) suggested that work-family enrichment best captures the mechanism of the positive work-family interface, and they defined work-family enrichment as 'the extent to which experiences in one role improve the quality of life in another role' (p. 73). They also developed a theoretical model of the work-family enrichment process, with a focus on two paths to promote work-family enrichment: an instrumental path and an affective path. Thus, workfamily enrichment represents how family roles benefit through developmental resources and positive affect derived from involvement in work. Similarly, family-work enrichment denotes how work roles benefit from family involvement via the same processes (Brough, Hassan, \& O'Driscoll, in press). This emerging focus on work-family enrichment supplements the dominant conflict perspective by identifying new ways of cultivating human resources.

Carlson et al. (2006) described the bi-directional and multidimensional concept of work-family enrichment that work and family provide individuals with somewhat distinct resources that can be used to improve role performance and quality of life in other domains. Accordingly, work-to-family enrichment (WFE) consists 
of three dimensions of gains from work to family (development, affect and capital), while family-to-work enrichment (FWE) consists of three dimensions of gains from the family to work (development, affect and efficiency). The present study adds to the literature by investigating the antecedents of the three dimensions and both directions of work-family enrichment.

Kossek, Baltes, and Matthews (2011) have recently suggested that there is limited international sampling in work-family studies. Cultural characteristics and the macro-environment in Chinese society may elicit different opportunities for individuals to achieve workfamily enrichment than in Western societies. Compared with their individualistic counterparts, Chinese tend to place more emphasis on work than on leisure, have less concern about work intruding on non-work and see work as contributing to the family rather than competing with it. Such a collectivistic perspective helps alleviate work-family pressure, and thus, Chinese workers seem to experience less work-family conflict than workers from Western societies (e.g. Spector et al., 2007; Yang, 2005). Under the influence of Confucianism and Buddhism, harmonious relationships are important for Chinese people. Following arguments presented by Spector and his colleagues (2007) on work-family conflict, one would expect that the quality of the relationship with the supervisor would be better, job satisfaction higher and WFE would be more likely to occur among Chinese employees. Similarly, as part of Confucian values, family relations among Chinese are also very important. Thus, perceiving family support will most likely result in family satisfaction, which in turn, may yield higher levels of FWE. China is therefore a very interesting context to examine work-family enrichment processes.

In addition, as China is transforming into a market economy-oriented society, social modernization is also creating rapid change in both work and lifestyles, resulting in potentially more interference and interactions between the work and family domains (Lu, Shi, \& Lawler, 2002; Siu, Spector, Cooper, \& Lu, 2005). Whereas several work-family studies have been conducted in China including studies comparing China with Western societies, the results are inconsistent, and the underlying process is still unclear ( $\mathrm{Lu}, \mathrm{Siu}$, Chen, \& Wang, 2011; Lu, Siu, Spector, \& Shi, 2009; Spector et al., 2007; Tang, Siu, \& Cheung, 2012; Yang, Chen, Choi, \& Zou, 2000). Additionally, work-family enrichment research has long been criticized for an overreliance on cross-sectional data (e.g. Casper, Eby, Bordeaux, Lockwood, \& Burnett, 2007). In the present study, we investigate the process through which work may enrich the family and vice versa. We will focus on social support as possible resources in both domains that may spill over to the other domain through positive affect and satisfaction with the life domain. Moreover, we will use a longitudinal design in order to test the causal ordering of the model variables.

\section{Theory and hypotheses}

\section{Resource conservation, resource gain and work-family enrichment}

According to the conservation of resources (COR) theory (Hobfoll, 1989), '...people strive to retain, protect, and build resources and what is threatening to them is the potential or actual loss of these valued resources' (p. 516). Hobfoll (1989) suggested that in order to develop and gain more resources, people would employ resources that they possess or call on resources that are available to them from their environment. There is some empirical evidence showing that resources generated in the family role can improve work role performance through an instrumental (i.e. direct) path (e.g. Demerouti, Bakker, \& Voydanoff, 2010; Graves, Ohlott, \& Ruderman, 2007; Greenhaus \& Powell, 2006; Hunter, Perry, Carlson, \& Smith, 2010; Weer, Greenhaus, \& Linnehan, 2010).

As a key resource in the COR model, social support has two major functions. It serves to protect existing available resources and to enable individuals to obtain new resources. Adams, King, and King (1996) differentiated work-related support (e.g. supervisory support) from non-work-related social support (e.g. family support). Many studies on the work-family interface have shown domain-specific effects of social support. For instance, social support from supervisors or colleagues is more strongly (negatively) related to work-to-family conflict, whereas social support from the spouse is more strongly (negatively) related to family-to-work conflict (e.g. Bellavia \& Frone, 2005). Moreover, Wayne et al. (2007) introduced the resource-gain-development (RGD) perspective to study work-family facilitation, which is consistent with the domain-specific model of work-family enrichment. They suggested that the key enablers of growth and development-and consequently also of work-family enrichment-are personal and environmental resources in the originating domain. In our study, we focused on social support resources (supervisory support and family support) as one type of environmental resource and examined the impacts of different types of social support on work-family enrichment (i.e. WFE and FWE) through domain-specific outcomes (i.e. job satisfaction and family satisfaction).

\section{Supervisory support, job satisfaction and work-to-family enrichment}

Previous studies have shown that supervisory support is positively associated with job attitudes such as job satisfaction (Allen, 2001; Marcinkus, Whelan-Berry, \& Gordon, 2007). These findings can be explained by social exchange theory (Blau, 1964), which states that individuals reciprocate in the form of more favourable attitudes toward the domain that is perceived as the originator of a resource. Reciprocity or bao is one of 
the social beliefs in Chinese culture (Leung, 2010). Applying this to work-family enrichment, employees and their supervisors have an exchange relationship with each other. For instance, when employees perceive their supervisors as being more supportive, they feel obligated to reciprocate with positive feeling toward the job and the organization, and they put in increased effort (Aryee, Srinivas, \& Tan, 2005; Rhoades \& Eisenberger, 2002; Tang et al., 2012).

Consistent with the affective path advocated by Greenhaus and Powell (2006), support from supervisors could help to promote the focal employee's job performance. This would result in satisfaction with one's job role, which in turn may spill over to the family domain and improve family role performance. Rothbard (2001) also indicated that greater attentiveness in one domain is indirectly associated with enhanced engagement in another domain through positive affect. For instance, in a recent quantitative diary study among Spanish working couples, RodríguezMuñoz, Sanz-Vergel, Demerouti, and Bakker (in press) found that employees' daily work engagement spilled over to the home domain, increasing their own happiness level at the end of the day, and indirectly influencing the partner's happiness. Additionally, it has been found that enrichment can occur when the emotions and moods experienced in one role enrich another role, verifying the affective path (Hanson, Hammer, \& Colton, 2006). Furthermore, as outlined by Wayne et al. (2007), employees experiencing positive affect at work transfer their good mood to their family. In the current study, we focused on job satisfaction as an affect mediating path because not only it represents an affective reaction to job (Cranny, Smith, \& Stone, 1992; Judge, Hulin, \& Dalaal, in press) but also it captures an individual's satisfaction with job role in Greenhaus and Powell's (2006) work-family enrichment model. Thus, on the basis of social exchange theory, domain-specific effects of social support, and the RGD perspective (e.g. Allen, 2001; Aryee et al., 2005; Wayne et al., 2007), we hypothesize that individuals will experience WFE directly when they receive supervisor support at work and that supervisory support will also contribute positively and indirectly to WFE via job satisfaction. Hence, the following mediation hypothesis is posited:

Hypothesis 1: Job satisfaction partially mediates the positive relationship between supervisory support and WFE (development, affect and capital).

\section{Family support, family satisfaction and family-to-work enrichment}

Family support may play an extrinsic motivational role by providing instrumental advice to help employees in achieving their work goals (Grzywacz \& Marks, 2000). Additionally, family support (e.g. spouse support) would also make people experience more positive affect such as positive mood, satisfaction with family roles and psychological well-being by providing emotional support. According to the COR theory (Hobfoll, 1989), in order to develop and gain more resources, people utilize resources that they possess or call on resources that are available to them from their environment. In collectivistic societies, family support seems to be especially important in motivating employees to work harder at their jobs (Lu et al., 2011; Tang et al., 2012).

Drawing on the tenets of the RGD perspective (Wayne et al., 2007), employees experiencing positive affect in family life may transfer their good mood to work settings. Stevens, Minnotte, Mannon, and Kiger (2007) found that satisfaction with their partner's emotion work (e.g. providing encouragement to their partners) was positively related to FWE for both men and women. Empirical studies also provided evidence that family support is stronger positively related to FWE than WFE (Aryee et al., 2005; Wayne, Randel, \& Stevens, 2006). In collectivistic cultures, family life and work life are likely to be perceived as being connected rather than distinct (e.g. Daly, Jennings, Beckett, \& Leashore, 1995; Trompenaars \& Hampden-Turner, 1998). A recent study by Lu et al. (2009) found that support from elderly domestic helpers and spouses had significant positive effects on the facilitation component of work-family balance. More recently, Lu et al. (2011) reported that family mastery enhanced work engagement-a work-related positive affect in a sample of Chinese nurses. We extend their studies to investigating the mediating role of family satisfaction that acts as an affective path in Greenhaus and Powell's (2006) work-family enrichment model. We posit that individuals will experience FWE directly when they receive family support, which will also contribute positively and indirectly to FWE via family satisfaction.

Hypothesis 2: Family satisfaction partially mediates the relationship between family support and FWE (development, affect and efficiency).

\section{Method}

We utilized a three-wave self-administered questionnaire survey for testing the hypotheses. We assessed predictor variables at time 1 , mediating variables at time 2 and criterion variables at time 3. A 6-month time lag was specified between the first (T1) and the second (T2) waves, and another 6-month time lag between the second and the third waves (T3). In the past, the time lag adopted by longitudinal studies in the work-family interface ranged from 6 weeks to 6 years, with most studies reporting a time lag of 1 year (Brough et al., 2013; Demerouti, Bakker, \& Bulters, 2004; O’Driscoll, Brough, \& Kalliath, 2004; Peeters, de Jonge, Janssen, \& van der Linden, 2004; Rantanen, Kinnunen, Feldt, \& Pulkkinen, 2008). In 
this study, we conducted a three-wave study with a 6 -month time lag between consecutive waves. The span of 6 months was chosen to provide ample separation between our measures while not spacing surveys so far apart as to increase participant attrition.

\section{Participants and procedures}

The respondents were drawn from an eye glasses factory in Dongguan, China. On behalf of the research team, the factory's human resource department sent invitation letters to all employees requesting them to participate in the survey three times. Employees were assured of the confidentiality of their response and were informed in the invitation letter that their participation was voluntary. Employees were told that the objective of the survey was to evaluate the effectiveness of work-life policies in terms of business outcomes and measuring individual health outcomes. Sealed completed questionnaires were returned to a designated person in the human resources department.

During the first wave (time 1) in December 2007, two research assistants distributed the questionnaires to employees within the factory. The response rate was $90 \%(N=3137)$ out of 3500 workers in the first wave of data collection, and the second wave survey was administered to the 3137 respondents 6 months later after the first wave. After matching the two survey data using a matching code (the matching code was composed of three letters of respondents' mothers' maiden name, two digits of date of birth and two digits of month of birth),we achieved a time 1 and time 2 matched sample of 713 employees (23\%). Six months after the second wave, research assistants administered the third survey to the 713 participants, and by the same matching procedure, we achieved a three-wave matched sample of 276 (39\%) of full-time workers. The low matched rate may be because some participants forgot their codes created at T1 or they did not create their codes at T1 or T2. Furthermore, there are not many varieties of surnames in Chinese; hence, there were many coincidences of codes in the sample that made it difficult for us to identify the matched ones. There were no significant differences between the T3 sample of 276 workers and the original T1 3137 respondents in terms of gender, organizational tenure and marital status. We also compared the time 1 sample of 276 workers and the original 3137 respondents in terms of supervisor support and family support measured at $\mathrm{T} 1$ and between the 276 workers and the 713 respondents in terms of job satisfaction and family satisfaction measured at T2. No significant difference was found in any of these tests.

At time 1, the respondents ranged in age from 18 to 39 years $[M=23.3$, standard deviation $(S D)=4.0]$, and their average organizational tenure was 3.5 years $(\mathrm{SD}=$ $1.8)$. Over half $(70 \% ; n=193)$ of the respondents were single or never married, $73(29 \%)$ were married or cohabitating, most of them were women $(71 \%, n=197)$ and $172(62 \%)$ were living with family member(s).

\section{Measures}

The survey instruments were administered in Chinese. The translation and back translation procedure was performed on measures that do not have Chinese versions (Brislin, 1980).

Supervisory support and family support were measured at time 1 (T1) with eight items developed by O'Driscoll et al. (2004). Respondents were asked how often they had received four different types of support from their supervisor and their family: 'helpful information or advice', 'sympathetic understanding and concern', 'clear and helpful feedback' and 'practical assistance'. A 6-point response scale was used, where $1=$ 'never' and $6=$ 'all the time'. Internal consistency (Cronbach's alphas) for the measures of supervisor support and family support were 0.85 and 0.86 , respectively.

Job satisfaction was measured at T2 by three items from Cammann, Fichman, Jenkins, and Klesh (1979) using a 5-point scale with responses ranging from 1 ('strongly disagree') to 5 ('strongly agree'). A sample item is 'All in all I am satisfied with my job'. Alpha was 0.73 .

Family satisfaction was also measured at T2 by three items from Edwards and Rothbard (1999) using a 7-point scale with responses ranging from 1 (strongly disagree) to 7 (strongly agree). A sample item is 'In general, I am satisfied with my family/home life'. Alpha was 0.91 .

Work-to-family enrichment was measured at T3 using the nine-item scale by Carlson et al. (2006) containing three dimensions-development, affect and capital. Ratings were completed on a 5-point scale ranging from $1=$ strongly disagree to $5=$ strongly agree . A sample item for development is 'My work helps me to understand different viewpoints and this helps me be a better family member', a sample item for affect is 'My work puts me in a good mood and this helps me be a better family member' and a sample item for capital is 'My work provides me with a sense of accomplishment and this helps me be a better family member'. The alphas were $0.71,0.90$ and 0.83 for development, affect and capital, respectively.

Family-to-work enrichment was measured at T3 using the nine-item scale by Carlson et al. (2006) containing three dimensions-development, affect and efficiency. Ratings were completed on a 5-point scale ranging from $1=$ strongly disagree to $5=$ strongly agree. A sample item for development is 'My family helps me to gain knowledge and this helps me be a better worker', a sample item for affect is 'My family makes me feel happy and this helps me be a better worker' and a sample item for efficiency is 'My family requires me to avoid wasting time at work and this helps me be a better worker'. The alphas were 0.75 , 
0.92 and 0.83 for development, affect and capital, respectively.

\section{Data analysis}

Considering the potential problem of common method variance, the Harman's single-factor test was conducted to examine whether a general factor emerged and accounted for most of the covariance among the measures. In this statistical procedure, all the items were entered into an exploratory factor analysis with un-rotated principal axis factoring. If a substantial amount of common method variance is present, a single factor will emerge from the factor analysis, or one general factor will account for the majority of the covariance among variables.

The Amos 19.0 programme was used to conduct confirmative factor analysis before testing our hypothesized relationships. The analysis was performed on variance-covariance matrices. We specified all 10 latent variables (the time 1 measures of supervisory support and family support, the time 2 measures of job satisfaction and family satisfaction and the time 3 measures of WFE-development, WFE-affect, WFE-capital, FWEdevelopment, FWE-affect and FEW-efficiency) into a single confirmative factor analysis. The fit of the measurement model to the data was assessed with the chi-squared $\left(\chi^{2}\right)$ statistic, the goodness of fit index (GFI), the Root Mean Square Error of Approximation (RMSEA), the comparative fit index (CFI), the incremental fit index (IFI), the Akaike information criterion (AIC) and the Tucker-Lewis index (TLI). For GFI, CFI, IFI and TLI, values closed to 0.95 or greater are desirable, whereas RMSEA should preferably be less than 0.05 ; for AIC, ranging from $-\infty$ to $+\infty$ and generally used to compare competing models, the model with the lowest AIC is preferred (Hu \& Bentler, 1999).

Correlations were computed as an initial test of the hypotheses. We used structural equation modelling with bootstrapping to test whether the significant pathways running between support at $\mathrm{T} 1$ and enrichment at T3 through satisfaction at T2. Specifically, we tested the bi-directional process model of work-family enrichment separately and the antecedents of sub-dimensions of WFE and FWE rather than overall score of subdimensions. Bootstrapping is a statistical re-sampling method that estimates the parameters of a model and their standard errors strictly from the sample (Preacher \& Hayes, 2008). We extracted new samples (with replacement) from our sample 2000 times and calculated the estimates of the mediation effects (Preacher \& Hayes, 2008).

\section{Results}

\section{Harman's single-factor test, confirmative factor analysis and descriptive statistics}

The results of Harman's single-factor test showed that 10 factors emerged with an eigenvalue greater than 1 . The 10 un-rotated factors together accounted for $75.01 \%$ of variance, suggesting that common method variance was not of great concern and was unlikely to significantly confound the interpretation of results. We then conducted confirmatory factor analysis to test the validity of our measurement model. The hypothesized 10-factor model showed an acceptable fit to the data $\left[\chi^{2}=609.16\right.$, degrees of freedom $(\mathrm{df})=419, \chi^{2} /$ $\mathrm{df}=1.35, \mathrm{GFI}=0.88, \mathrm{CFI}=0.98, \mathrm{IFI}=0.98, \mathrm{TLI}=0.97$, RMSEA $=0.038$, with factor loadings ranging from 0.61 to 0.92 , thus supporting the validity of the constructs measured. Table I shows the means, SDs, correlations and alpha coefficients for the main variables.

\section{Testing hypothesis 1}

Alternative structural models were tested against each other to test the research hypotheses. Specifically, the hypothesized WFE model (model A1) was compared with a competing full mediation model (model B1) in which all path coefficients from supervisor support to development, affect and capital were constrained to zero and to a competing direct effects model (model $\mathrm{C1}$ ) in which all path coefficients to and from job

Table I. Descriptive statistics, correlations and reliabilities for study variables ( $N=276)$

\begin{tabular}{lcccccccccccc}
\hline & Mean & SD & 1 & 2 & 3 & 4 & 5 & 6 & 7 & 8 & 9 & 10 \\
\hline 1. Supervisor support T1 & 2.72 & 0.88 & $(0.85)$ & & & & & & & & \\
2. Family support T1 & 4.00 & 1.05 & $0.12^{*}$ & $(0.86)$ & & & & & & & \\
3. Job satisfaction T2 & 3.17 & 0.71 & $0.21^{* *}$ & -0.09 & $(0.73)$ & & & & & & \\
4. Family satisfaction T2 & 5.25 & 1.47 & $0.13^{*}$ & $0.16^{* *}$ & 0.11 & $(0.91)$ & & & & & \\
5. Work-to-family development T3 & 3.39 & 0.65 & $0.24^{* *}$ & -0.03 & $0.16^{* *}$ & 0.05 & $(0.71)$ & & & & \\
6. Work-to-family affect T3 & 3.03 & 0.80 & $0.16^{* *}$ & -0.05 & $0.21^{* *}$ & 0.07 & $0.53^{* *}$ & $(0.90)$ & & & \\
7. Work-to-family capital T3 & 3.12 & 0.74 & $0.24^{* *}$ & -0.02 & $0.22^{* *}$ & $0.14^{*}$ & $0.45^{* *}$ & $0.55^{* *}$ & $(0.83)$ & & \\
8. Family-to-work development T3 & 3.57 & 0.59 & $0.16^{* *}$ & 0.12 & 0.09 & $0.13^{*}$ & $0.55^{* *}$ & $0.32^{* *}$ & $0.39^{* *}$ & $(0.75)$ & \\
9. Family-to-work affect T3 & 3.65 & 0.70 & 0.08 & 0.09 & 0.01 & $0.17^{* *}$ & $0.36^{* *}$ & $0.29^{* *}$ & $0.19^{* *}$ & $0.45^{* *}$ & $(0.92)$ \\
10. Family-to-work efficiency T3 & 3.65 & 0.71 & 0.10 & 0.05 & 0.00 & $0.16^{* *}$ & $0.41^{* *}$ & $0.22^{* *}$ & $0.19^{* *}$ & $0.43^{* *}$ & $0.49^{* *}$ & $(0.83)$ \\
\hline
\end{tabular}

SD: standard deviation; T1: time 1; T2: time 2; T3: time 3.

Alphas are in parentheses on the diagonal.

${ }^{*} p<0.05 .{ }^{* *} p<0.01$. 
satisfaction were constrained to zero. As shown in Table II, model A1 produced a significantly better fit to the data than model B1 $\left(\chi^{2}=15.29, \mathrm{df}=3, p<0.01\right.$; $\mathrm{AIC}=-9.31)$ and model $\mathrm{C} 1\left(\chi^{2}=22.60, \mathrm{df}=4\right.$, $p<0.001 ; \mathrm{AIC}=-3.54)$. Therefore, we conclude that model A1, a partial mediation WFE model, provided the most parsimonious fit to the data (Figure 1).

The bootstrap analyses confirmed the indirect effects of supervisory support at $\mathrm{T} 1$ on affect [bootstrap estimate $=0.06$, standard error $=0.03$, lower confidence interval $(\mathrm{CI})=0.01$, higher $\mathrm{CI}=0.11, p<0.05]$ and on capital (bootstrap estimate $=0.05$, standard error $=$ 0.02 , lower $\mathrm{CI}=0.01$, higher $\mathrm{CI}=0.09, \quad p<0.05$ ) through job satisfaction at T2 but not on development (bootstrap estimate $=0.04$, standard error $=0.02$, lower $\mathrm{CI}=-0.01$, higher $\mathrm{CI}=0.09, p>0.05)$. As shown in Figure 1, supervisory support had significant direct effects on capital $(\beta=0.21, p<0.01)$ and development $(\beta=0.27, \quad p<0.001)$. Additionally, the bootstrap analyses showed that the total effects of supervisory support on affect (bootstrap estimate $=0.17$, standard error $=0.07$, lower $\mathrm{CI}=0.04$, higher $\mathrm{CI}=0.31, p<0.05$ ), capital (bootstrap estimate $=0.26$, standard error $=0.07$, lower $\mathrm{CI}=0.11$, higher $\mathrm{CI}=0.40, p<0.01$ ) and development (bootstrap estimate $=0.31$, standard error $=0.08$, lower $\mathrm{CI}=0.15$, higher $\mathrm{CI}=0.46, p<0.01$ ) were all significant.

These results indicated that job satisfaction partially mediated the relationship between supervisory support and capital and fully mediated the relationship between supervisory support and affect. In other words, employees who perceived more supervisory support experienced more job satisfaction; they then as a member of the family perceived higher levels of security, confidence and accomplishment (i.e. work-to-family capital) and more positive emotional states (i.e. work-to-family affect). Thus, hypothesis 1 was partially supported.

\section{Testing hypothesis $\mathbf{2}$}

The hypothesized FWE model (model A2) was also compared with a competing full mediation model (model B2) in which all path coefficients from family

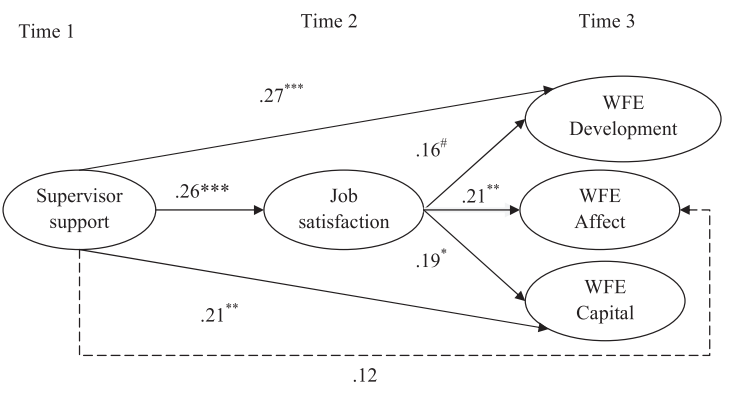

Figure 1. Standardized path coefficients for the work-to-family enrichment model $(N=276)$

support to development, affect and efficiency were constrained to zero and to a competing direct effects model (model C2) in which all path coefficients to and from family satisfaction were constrained to zero. As shown in Table II, model A2 produced a significantly better fit to the data than model C2 $\left(\chi^{2}=15.21, \mathrm{df}=4\right.$, $p<0.01$; $\mathrm{AIC}=-7.22)$. However, model B2 was significantly better than model A2 $\left(\chi^{2}=3.17, \mathrm{df}=3, p>0.05\right.$; $\mathrm{AIC}=-2.83)$. Therefore, we accepted model B2, which is a full mediation FWE model (Figure 2).

The bootstrap analyses confirmed that the indirect effects of family support at T1 on affect (bootstrap estimate $=0.03$, standard error $=0.02$, lower $\mathrm{CI}=0.00$, higher $\mathrm{CI}=0.08, p<0.05$ ) and on efficiency (bootstrap estimate $=0.03$, standard error $=0.02$, lower $\mathrm{CI}=0.00$, higher $\mathrm{CI}=0.07, p<0.05)$ through family satisfaction at $\mathrm{T} 2$ but not on development (bootstrap estimate $=$ 0.03 , standard error $=0.02$, lower $\mathrm{CI}=-0.00$, higher $\mathrm{CI}=0.07, p>0.05)$. Additionally, the bootstrap analyses showed that the total effects of family support on affect (bootstrap estimate $=0.03$, standard error $=0.02$, lower $\mathrm{CI}=0.00$, higher $\mathrm{CI}=0.08, p<0.05$ ) and efficiency (bootstrap estimate $=0.03$, standard error $=$ 0.02 , lower $\mathrm{CI}=0.00$, higher $\mathrm{CI}=0.07, p<0.05$ ) were significant but not development (bootstrap estimate $=$ 0.03 , standard error $=0.02$, lower $\mathrm{CI}=-0.00$, higher $\mathrm{CI}=0.07, p>0.05)$.

Table II. Model fit summary and structural models comparison $(N=276)$

\begin{tabular}{|c|c|c|c|c|c|c|c|c|}
\hline Model & $\chi^{2}$ & df & GFI & CFI & IFI & TLI & AIC & RMSEA \\
\hline \multicolumn{9}{|l|}{ Work-to-family enrichment model } \\
\hline 1. Partial mediation model (model A1) & $155.52^{\star \star}$ & 94 & 0.93 & 0.97 & 0.97 & 0.96 & 239.50 & 0.049 \\
\hline 2. Full mediation model (model B1) & $170.81^{\star *}$ & 97 & 0.93 & 0.96 & 0.96 & 0.95 & 248.81 & 0.053 \\
\hline 3. Direct model (model C1) & $178.12^{* *}$ & 98 & 0.93 & 0.97 & 0.97 & 0.96 & 243.04 & 0.051 \\
\hline \multicolumn{9}{|l|}{ Family-to-work enrichment model } \\
\hline 4. Partial mediation model (model A2) & $135.45^{*}$ & 94 & 0.94 & 0.98 & 0.98 & 0.98 & 220.08 & 0.040 \\
\hline 5. Full mediation model (model B2) & $138.62^{\star}$ & 97 & 0.94 & 0.98 & 0.98 & 0.98 & 217.25 & 0.040 \\
\hline 6. Direct model (model C2) & $150.66^{\star \star}$ & 98 & 0.94 & 0.98 & 0.98 & 0.97 & 227.30 & 0.045 \\
\hline
\end{tabular}

GFI: goodness of fit index; RMSEA: Root Mean Square Error of Approximation; CFI: comparative fit index; IFI: incremental fit index; AIC: Akaike information criterion; TLI: Tucker-Lewis index.

${ }^{*} p<0.01 .{ }^{* *} p<0.001$. 


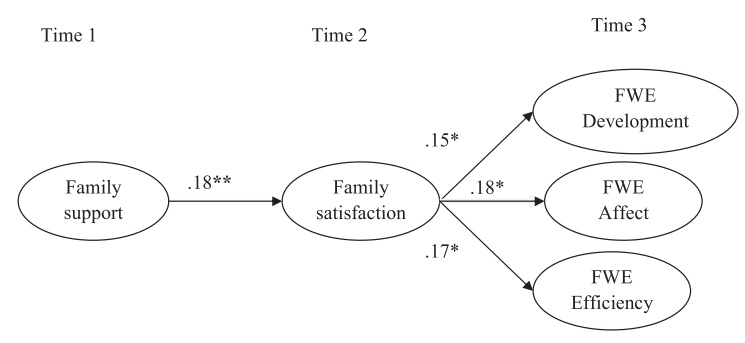

Figure 2. Standardized path coefficients for the family-to-work enrichment model $(N=276)$

These results indicated that family satisfaction fully mediated the relationships between family support and affect and efficiency. It appears that family support enhanced individuals' positive and satisfying feeling towards family, which in turn helped them to be a better worker by improvement of positive emotional states (i.e. family-to-work affect) and having a sense of focus or urgency (i.e. family-to-work efficiency). Hence, hypothesis 2 was partially supported.

\section{Discussion}

The purpose of the present study was to test a model of work-family enrichment using a three-wave survey in China. The first process tested social resources (supervisory support and family support) as antecedents, WFE and FWE as outcomes, and the second process tested social resources (supervisory support and family support) as antecedents, WFE and FWE as outcomes, with affect (job satisfaction and family satisfaction) as mediating variables. We found that time 2 job satisfaction partially mediated the relationship between time 1 supervisory support and time 3 WFE capital, whereas job satisfaction fully mediated the effect of supervisory support on work-to-family affect. In addition, time 2 family satisfaction fully mediated the relationship between time 1 family support and time 3 FWE affect and efficiency. However, the mediation effect of job (family) satisfaction in the relationship between supervisor (family) support and WFEdevelopment (FWE-development) was not significant. The findings suggest that when employees receive more support from their supervisor, they are more satisfied with their job. This job satisfaction seems to spill over to the home domain: higher job satisfaction translates into positive experiences in the family domain, including feelings of security, confidence and accomplishment (i.e. work-to-family capital) and positive affect. Similarly, when employees receive more support from their family at home, they feel more satisfied and come to work in a positive mood and with a sense of urgency.

This study is one of very few that has examined affect as a mediator (see Rothbard, 2001, for another example) in work-family enrichment research-in particular in a Chinese context. Our findings therefore provide preliminary empirical evidence offering a more complete understanding of positive work-family linkages (work-to-family and family-to-work) in the Carlson et al. (2006) work-family enrichment model. In the present research, we treated satisfaction with job and family as affective responses, which can positively improve the quality of life in the other domain. As argued earlier, our findings can be explained by social exchange theory (similar to reciprocity or bao) (Blau, 1964; Leung, 2010). Perhaps because our samples are Chinese, and the contribution and need for a family was much more important in their lives (Tang et al., 2012); thus, the findings of family satisfaction being a mediator between family support and family-to-work enrichment are more consistent than those found in WFE. Scholars have noted that more research on the antecedents of family-to-work enrichment is needed as there is a paucity of such studies in the work-family literature (Jones, Burke, \& Westman, 2006; Kofodimos, 1993). Our study has added to Lu et al. (2011) finding that family support is an indirect antecedent of familyto-work enrichment via family satisfaction, thus filling this gap of knowledge and contributed to Western theories in work-family literature.

\section{Contributions of the present study}

The current study offers a significant contribution to the extension, validation and generalization of Western theories. The present study also further supports the COR theory (Hobfoll, 1989) and the RGD perspective (Wayne et al., 2007)-testing a bi-directional process model of work-family enrichment linking differential social resources and affect. To date, few studies have examined the differential impact of specific social resources on WFE and FWE respectively, to confirm the domain-specific effects of social support. Thus, our study contributes to this literature by adopting a three-wave survey design, on the basis of the COR theory and the RGD perspective.

To date, this is the first longitudinal study adopting a three-wave design in a Chinese context, which is especially valuable for testing assumptions about causality of the three dimensions of the bi-directional work-family enrichment processes and extends previous findings on work-family enrichment research in Chinese societies. Therefore, our study directly contributes to the growing work-family enrichment literature. Whilst work-family enrichment is becoming a topic of popular national concern, mainland China is under-represented in this pool of academic knowledge. As mentioned earlier, research has found that, in a collectivistic culture, people tend to have closer ties to extended family members who provide both material and social support for family responsibilities (e.g. Daly et al., 1995; Ling \& Powell, 2001; Ryan, Leong, \& Oswald, 2012; Spector et al., 2007; Trompenaars \& Hampden-Turner, 1998). It is therefore valuable to test 
Western theories of work-family enrichment within the Chinese context (Kossek et al., 2011).

\section{Research limitations}

Several limitations of this study should be noted. Firstly, we were not able to collect performance data in the work and family domains, in order to directly assess role performance. Secondly, the study was based on self-reports, which may raise questions of commonmethod bias (e.g. Podsakoff, MacKenzie, Lee, \& Podsakoff, 2003). However, the predictors, mediators and outcomes were separated in time from each other, which could lower the likelihood of finding correlations which are simply because of response consistency. In addition, the results from the Harman's single-factor test also showed common-method variance was not a major problem in the present study. Thirdly, unexpectedly, we found that supervisory support did not have a direct effect on work-to-family affect enrichment, while family support did not have a direct positive effect on the three dimensions of family-to-work enrichment. However, we cannot exclusively attribute these differences to the impact of collectivistic culture, since we did not directly assess cultural variables in our study. Future research needs to examine the cross-cultural generalizability of our findings.

\section{Practical implication of the findings}

The findings of our study highlight the importance of social support in helping employees to integrate their work and family life. The positive impact of supervisor and family support on work-family enrichment has implications for both managers and family members, because social support provided in one domain not only improves employees' evaluation of role experiences in that domain but also has beneficial influence on the other domain (Westman, Brough, \& Kalliath, 2009). Recognition of the interdependence between work and family domains provides an impetus for both managerial and family members to support skilled workers.

Another important finding in the current study concerns the mediating effect of job and family satisfaction, which suggests that positive evaluations of role experiences in one domain are important for affect in the other domain. This finding has direct implications for both employees and organizations. Employees need to be aware that quality role experiences, rather than reduced participation in one domain, can enable cross-domain enrichment. They could direct their efforts to enhancing the quality of role experiences in each domain, for example, by working more efficiently or providing better service at work or by spending quality time with family. At the organizational level, our findings reveal the importance of valuing employees' family lives, because quality family life will in turn enhance employees' role performance at work. In addition, the findings provide empirical evidence that investment into cultivating employees' job satisfaction or positive affect is important, because it may have a positive impact beyond the workplace (Poelmans, Kalliath, \& Brough, 2008). In sum, the impact of supervisor and family support on work-family enrichment warrants further attention.

\section{Conclusion}

The proposed bi-directional processes of work-family enrichment were found in this three-wave study using Chinese sample. Supervisory support can indirectly promote individuals' affect and capital as family members through enhancing the feeling of job satisfaction, while family support can also indirectly promote individuals' affect and efficiency as work members through enhancing the feeling of family satisfaction. In addition, supervisory support also had a directly positive effect on individuals' development and capital as family members.

\section{Conflict of interest}

The authors have declared that they have no conflict of interest.

\section{Acknowledgments}

This work has been supported by the RGC research grants in Lingnan University (Project Nos. DR07B7, DS08A4 and DR09A2). Portion of the paper was presented at the 2011 Academy of Management Annual Meeting, San Antonio, USA, on 16 August, 2011.

\section{REFERENCES}

Adams, G. A., King, L. A., \& King, D. W. (1996). Relationships of job and family involvement, family social support, and work-family conflict with job and life satisfaction. Journal of Applied Psychology, 81, 411-420. Allen, T. D. (2001). Family-supportive work environments: The role of organizational perceptions. Journal of Vocational Behavior, 58, 414-435.

Aryee, S., Srinivas, E. S., \& Tan, H. H. (2005). Rhythms of life: Antecedents and outcomes of work-family balance in employed parents. Journal of Applied Psychology, 90, 132-146.

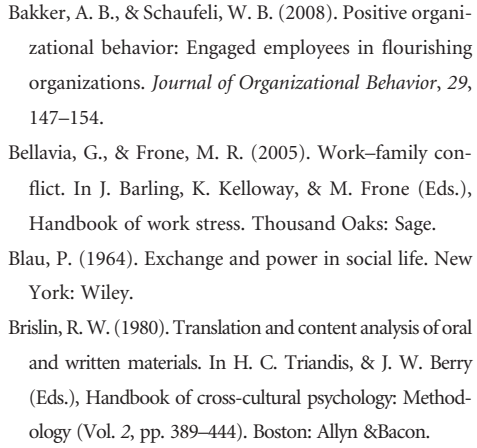

Bakker, A. B., \& Schaufeli, W. B. (2008). Positive organizational behavior: Engaged employees in flourishing organizations. Journal of Organizational Behavior, 29, 147-154.

Bellavia, G., \& Frone, M. R. (2005). Work-family conflict. In J. Barling, K. Kelloway, \& M. Frone (Eds.), Handbook of work stress. Thousand Oaks: Sage.

Blau, P. (1964). Exchange and power in social life. New York: Wiley.

Brislin, R. W. (1980). Translation and content analysis of oral and written materials. In H. C. Triandis, \& J. W. Berry (Eds.), Handbook of cross-cultural psychology: Methodology (Vol. 2, pp. 389-444). Boston: Allyn \&Bacon.

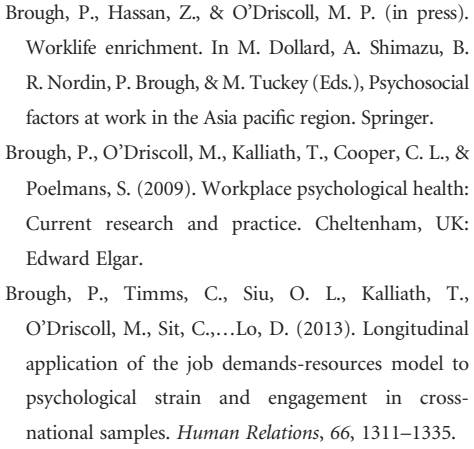


Cammann, C., Fichman, M., Jenkins, D., \& Klesh, J. (1979). The Michigan organizational assessment questionnaire. Unpublished manuscript, University of Michigan, Ann Arbor.

Carlson, D. S., Kacmar, K. M.,Wayne, J. H., \& Grzywacz, J. G. (2006). Measuring the positive side of the work-family interface: Development and validation of a work-family enrichment scale. Journal of Vocational Behavior, 68, 131-164.

Casper, W. J., Eby, E. T., Bordeaux, C., Lockwood, A., \& Burnett, D. (2007). A review of research methods in IO/OB work-family research. Journal of Applied Psychology, 92, 28-43.

Cranny, C. J., Smith, P. C., \& Stone, E. F. (1992). Job satisfaction: How people feel about their jobs and how it affects their performance. New York: Lexington

Daly, A., Jennings, J., Beckett, J. O., \& Leashore, B. R. (1995). Effective coping strategies of African Americans. Social Work, 40, 240-248.

Demerouti, E., Bakker, A. B., \& Bulters, A. J. (2004). The loss spiral of work pressure, work-home interference and exhaustion: Reciprocal relations in a three-wave study. Journal of Vocational Behavior, 64, 131-149.

Demerouti, E., Bakker, A. B., \& Voydanoff, P. (2010). Does home life interfere with or facilitate performance? European Journal of Work and Organizational Psychology, 19, 128-149.

Eby, L. T., Casper, W. J., Lockwood, A., Bordeaux, C., \& Brinley, A. (2005). A retrospective on work and family research in IO/OB: A content analysis and review of the literature [Monograph]. Journal of Vocational Behavior, 66, 124-197.

Edwards, J. R., \& Rothbard, N. P. (1999). Work and family stress and well-being: An examination of person-environment fit in the work and family domains. Organizational Behavior and Human Decision Processes, 77, 85-129.

Graves, L., Ohlott, P., \& Ruderman, M. (2007). Commitment to family roles: Effects on managers' attitudes and performance. Journal of Applied Psychology, 92, 44-56

Greenhaus, J. H., \& Powell, G. N. (2006). When work and family are allies: A theory of work-family enrichment. Academy of Management Review, 31, 72-92.

Grzywacz, J. G., \& Marks, N. F. (2000). Reconceptualizing the work-family interface: An ecological perspective on the correlates of positive and negative spillover between work and family. Journal of Occupational Health Psychology, 5, 111-126.

Hanson, G., Hammer, L., \& Colton, C. (2006). Development and validation of a multidimensional scale of perceived work-family spill-over. Journal of Occupational Health Psychology, 11, 249-265.

Hobfoll, S. E. (1989). Conservation of resources: A new attempt at conceptualizing stress. American Psychologist, 44, 513-524.

Hu, L. T., \& Bentler, P. M. (1999). Cutoff criteria for fit indexes in covariance structure analysis: Conventional criteria versus new alternatives. Structural Equation Modeling: A Multidisciplinary Journal, 6(1), 1-55.

Hunter, E. M., Perry, S. J., Carlson, D. S., \& Smith, S. A. (2010). Linking team resources to work-family enrichment and satisfaction. Journal of Vocational Behavior, 77, 304-312.
Jones, F., Burke, R. J., \& Westman, M. (2006). Conclusion. In F. Jones, R. J. Burke, and M. Westman (Eds.). Work-life balance: A psychological perspective (pp. 290-296). Hove, UK: Psychology Press.

Judge, T. A., Hulin, C. L., \& Dalaal, R. S. (in press). Job satisfaction and job affect. In S. W. J. Kozlowski (Ed.), The Oxford handbook of industrial and organizational psychology. New York: Oxford University Press.

Kofodimos, J. (1993). Balancing act. San Francisco: JosseyBass.

Kossek, K., Baltes, B. B., \& Matthews, R. (2011). How work-family research can finally have an impact in organizations. Industrial and Organizational Psychology: Perspectives on Science and Practice, 4, 352-369.

Leung, K. (2010). Beliefs in Chinese culture. In H. Michael Bond, The handbook of Chinese psychology (pp. 221-240). New York: Oxford.

Ling, Y., \& Powell, G. N. (2001). Work-family conflict in contemporary China: Beyond an American-based model. International Journal of Cross-Cultural Management, 1, 357-373.

Lu, J. F., Shi, K., \& Lawler, J. (2002). A preliminary model of work-family conflict. Chinese Journal of Applied Psychology, 8, 45-52. (in Chinese)

Lu, J. F., Siu, O. L., Spector, P., \& Shi, K. (2009). Antecedents and outcomes of a four-fold taxonomy of work-family balance in Chinese employed parents. Journal of Occupational Health Psychology, 14, 182-192.

Lu, C. Q., Siu, O. L., Chen, W. Q., \& Wang, H. J. (2011). Family mastery enhances work engagement in Chinese nurses: A cross-lagged analysis. Journal of Vocational Behavior, 78, 100-109.

Marcinkus, W. C., Whelan-Berry, K. S. \& Gordon, J. R. (2007). The relationship of social support to the work-family balance and work outcomes of midlife women, Women in Management Review, 22, 86-111.

O'Driscoll, M., Brough, P., \& Kalliath, T. (2004). Workfamily conflict, psychological well-being, satisfaction and social support: A longitudinal study in New Zealand. Equal Opportunities International, 23, 36-56. Peeters, M. C., de Jonge, J., Janssen, P. P., \& van der Linden, S. (2004). Work-home interference, Job stressors, and employee health in a longitudinal perspective. International Journal of Stress Management, 11, 305-322.

Podsakoff, P. M., MacKenzie, S. B., Lee, J., \& Podsakoff, N. P. (2003). Common method biases in behavioral research: A critical review of the literature and recommended remedies. Journal of Applied Psychology, 88, 879-903.

Poelmans, S. A. Y., Kalliath, T., \& Brough, P. (2008). Achieving work-life balance: Current theoretical and practical issues. Journal of Management and Organisation, 14, 227-238.

Preacher, K. J., \& Hayes, A. F. (2008). Asymptotic and resampling strategies for assessing and comparing indirect effects in multiple mediator models. Behavior research methods, 40(3), 879-891.

Rantanen, J., Kinnunen, U., Feldt, T., \& Pulkkinen, L. (2008). Work-family conflict and psychological well-being: Stability and cross-lagged relations within one- and sixyear follow-ups. Journal of Vocational Behavior, 73, 37-51. Rhoades, L., \& Eisenberger, R. (2002). Perceived organizational support: A review of the literature. Journal of Applied Psychology, 87, 698-714.
Rodríguez-Muñoz, A., Sanz-Vergel, A. I., Demerouti, E., \& Bakker, A. B. (in press). Engaged at work and happy at home: A spillover-crossover model. Journal of Happiness Studies.

Rothbard, N. P. (2001). Enriching or depleting? The dynamics of engagement in work and family roles. Administrative Science Quarterly, 46, 655-684.

Ryan, A. M., Leong, F. T. L., \& Oswald, F. L. (2012). Introduction. In A. M. Ryan, F. T. L. Leong, \& F. L. Oswald (Eds.), Conducting multinational research: applying organizational psychology in the workplace (pp.3-8). Washington, DC: American Psychological Association. Seligman, M., \& Csikszentmihalyi, M. (2000). Positive psychology: An introduction. American Psychologist, 55, 5-14. Siu, O. L., Spector, P. E., Cooper, C. L., \& Lu, C. Q. (2005). Work stress, self-efficacy, Chinese work values and work well-being in Hong Kong and Beijing. International Journal of Stress Management, 12, 274-288.

Spector, P. E., Allen, T. D., Poelmans, S., Lapierre, L. M., Cooper, C. L., O’Driscoll, M.,... Widerszal-Bazyl, M. (2007). Cross-national differences in relationships of work demands, job satisfaction and turnover intentions with work-family conflict. Personnel Psychology, 60, 805-835.

Stevens, D. P., Minnotte K. L., Mannon S. E., \& Kiger, G. (2007). Examining the 'neglected side of the workfamily interface'-antecedents of positive and negative family-to-work spillover. Journal of Family Issues, $28,242-262$.

Tang, S., Siu, O. L., \& Cheung, F. (2012). A study of work-family enrichment among Chinese employees: The mediating role between work support and job satisfaction. Applied Psychology: An International Review. Article first published online 22 June: doi: 10.1111/j.1464-0597.2012.00519.x

Trompenaars, F., \& Hampden-Turner, C. (1998). Riding the waves of culture: Understanding cultural diversity in global business. New York, NY: McGraw-Hill.

Wayne, J. H., Grzywacz, J. G., Carlson, D. S., \& Kacmar, K. M. (2007). Work-family facilitation: A theoretical explanation and model of primary antecedents and consequences. Human Resource Management Review, 17, 63-76.

Wayne, J. H., Randel, A. E., \& Stevens, J. (2006). The role of identity and work-family support in workfamily enrichment and its work-related consequences. Journal of Vocational Behavior, 69, 445-461. Weer, C. H., Greenhaus, J. H., \& Linnehan, F. (2010). Commitment to nonwork roles and job performance: Enrichment and conflict perspectives. Journal of Vocational Behavior, 76, 306-316.

Westman, M., Brough, P., \& Kalliath, T. (2009). Expert commentary on work-life balance and crossover of emotions and experiences: Theoretical and practice advancements. Journal of Organizational Behavior, 30, 587-595.

Yang, N. (2005). Individualism-collectivism and workfamily interfaces: A Sino-US comparison. In S. A. Y. Poelmans (Ed.), Work and family an international research perspective (pp. 287-318). Mahwah, NJ: Erlbaum. Yang, N., Chen, C. C., Choi, J., \& Zou, Y. (2000). Sources of work-family conflict: A Sino-US comparison of the effects of work and family demands. Academy of Management Journal, 43, 113-123. 